\title{
Revista \\ Brasileira \\ de Enfermagem \\ REBEn \\ Práticas educativas desenvolvidas por enfermeiras: repercussões sobre vivências de mulheres na gestação e no parto
}

PESQUISA

\author{
Educational practices developed by nurses: \\ reflections on women's pregnancy and labor experiences \\ Prácticas educativas desarrolladas por enfermeras: \\ repercusiones sobre las experiencias de mujeres en el embarazo y parto
}

\author{
Jane Márcia Progianti', Rafael Ferreira da Costa" \\ ' Universidade do Estado do Rio de Janeiro, Faculdade de Enfermagem, \\ Departamento Materno-Infantil. Rio de Janeiro-RJ, Brasil. \\ "Secretaria Municipal de Saúde e Defesa Civil, Casa de Parto David Capistrano Filho. Rio de Janeiro-RJ, Brasil.
}

Submissão: 20-02-2011 Aprovação: 02-07-2012

\section{RESUMO}

Objetivou-se discutir as repercussões das práticas educativas desenvolvidas por enfermeiras sobre a vivência das mulheres na gravidez e no parto. Estudo qualitativo cuja coleta de dados ocorreu por meio de entrevista semiestruturada com dezesseis mulheres que pariram e que frequentaram os grupos educativos e consultas puerperais em uma Casa de Parto. A análise foi mediante as diretrizes de análise de conteúdo de Bardin. Os resultados mostraram que as práticas educativas foram reestruturantes para a vivência tranquila, formação do vínculo materno, livre expressão da sexualidade durante a gestação e sensações vividas no parto. Concluiu-se que a educação em saúde utilizada como instrumento do cuidar, oportuniza a adesão da mulher a práticas obstétricas menos intervencionistas.

Descritores: Enfermagem obstétrica; Educação em saúde; Saúde da mulher; Parto humanizado.

\section{ABSTRACT}

The objective was to discuss the impact of educational practices developed by nurses on the experience of women in pregnancy and childbirth. A qualitative study was carried out, whose data was collected through semi-structured interviews with sixteen women who gave birth and who attended the educational groups and puerperal consultations in a Birth Center. Analysis was done according to the guidelines for content analysis of Bardin. The results showed that the practices were essential for peaceful pregnancy experience, maternal bonding, free expression of sexuality during pregnancy and sensations experienced in childbirth. It was concluded that health education, used as an instrument of care, nurture the accession of women to less interventionist obstetric practices.

Key words: Education in health; Obstetric nursing; Woman's health; Humanizing delivery.

\section{RESUMEN}

El objetivo de este estudio fue analizar el impacto de las prácticas educativas desarrolladas por enfermeras en la experiencia de las mujeres en el embarazo y parto. Un estudio cualitativo fue desarrollado, cuyos datos fueron recolectados a través de entrevistas semi estructuradas con diez y seis mujeres que dieron a luz y que asistieron a los grupos de educación y consulta de puerperio en una casa de parto. El análisis fue efectuado según las directrices para análisis de contenido de Bardin. Los resultados mostraron que las prácticas eran reestruturantes para una vida pacífica, unión con la madre, la libre expresión de la sexualidad durante el embarazo y sensaciones experimentadas durante el parto. Se concluyó que la educación para la salud utilizado como un instrumento de cuidado, alimentación a la adhesión de las mujeres a prácticas obstétricas menos intervencionistas.

Palabras clave: Educación en salud; Enfermería obstétrica; Salud de la mujer; Parto humanizado. 


\section{INTRODUÇÃO}

Atualmente, muitas mulheres perderam o credo em sua capacidade de gestar e parir. Elas acreditam que precisam de um profissional munido de alta tecnologia e saber para realizar seu parto. Essa mentalidade decorre da forte e intrínseca cultura do parto hospitalar vigente, onde o parto natural ou fisiológico não é considerado seguro, ocorrendo a desvalorização dos conhecimentos e potenciais da mulher ${ }^{(1)}$. Assim, por terem sido socializadas nessa cultura acreditamos que algumas mulheres valorizam as ações intervencionistas, centradas no profissional.

No enfrentamento desta problemática na obstetrícia contemporânea, a educação em saúde é uma valiosa estratégia profissional enquanto alicerce da negociação do cuidado humanizado(2), e neste contexto, é entendida como uma prática educativa que trabalha junto ao indivíduo a visão crítica e libertadora das condições de vida, almejando estratégias de mudança em seu benefício e de sua comunidade ${ }^{(1)}$. Neste sentido, as práticas educativas desenvolvidas pelas enfermeiras no campo obstétrico são um instrumento de suas ações de cuidado que podem transformar a maneira de parir e nascer em confluência com a Política Nacional de Atenção Integral à Saúde da Mulher ${ }^{(3)}$, que enfatiza que a humanização da atenção em saúde envolve "compartilhar saberes" e "reconhecer direitos", percebendo, nas relações, os condicionantes sócioculturais, étnicos, raciais e de gênero.

Para o Ministério da Saúde ${ }^{(4)}$ a Educação em Saúde é uma prática centrada na sociedade e um processo que contribui para a formação e desenvolvimento da visão crítica das pessoas, a respeito de sua saúde, instigando a busca de soluções e a organização para a ação coletiva. Essa definição nos faz refletir que o modelo tradicional de cuidado pautado na mudança de hábitos individuais, tendo como fundamento pedagógico a transmissão dos conteúdos, precisa ser repensado, pois talvez não atenda as necessidades da população, já que vem sendo utilizado, ao longo da história pelos profissionais de saúde, sem surtir mudanças importantes na saúde das pessoas ${ }^{(5)}$.

Deste modo, partilhar saberes no intuito de prevenir, promover e recuperar a saúde através de ações educativas dá base à Educação em Saúde tornando-a uma prática educativa positiva porque é construída junto com a comunidade e não para ela, instrumentalizando-a e fomentando a percepção dos motivos e soluções para os problemas de saúde de maneira crítica $^{(6-7)}$.

Sabe-se que a associação do cuidado com as práticas educativas está no saudável compartilhar de práticas e saberes em uma relação horizontalizada onde a enfermeira exerce seu papel de cuidadora e educadora dividindo o seu saber e fazer e agregando o saber e o fazer popular, evitando, assim, posturas autoritárias. Nesta perspectiva, o cuidado de enfermagem no campo obstétrico torna-se, então, humanizado, porque considera as práticas culturais em saúde da população, abrindo um espaço de construção dos saberes a partir das práticas educativas. O que diferencia esse cuidado de outros é o seu potencial libertador e gerador de novos comportamentos de saúde da população e dos próprios profissionais de saúde envolvidos.
Cada mulher atribui um significado às experiências vividas e essas experiências serão utilizadas em outras vivências ${ }^{(8)}$. Cabe, então, à enfermeira amenizar, no caso de mulheres socializadas em um meio culturalmente medicalizado, o embate com a abordagem humanizada. Essa mediação pode acontecer através das ações educativas em saúde que não só respeitem a individualidade, mas permitam a tomada de decisão pelo ser cuidado. Deste modo, a educação em saúde pode atuar como um potencializador do cuidado da enfermeira, pois é capaz de gerar mudanças, o aprender mútuo e a construção de relações humanas simétricas ${ }^{(6)}$.

Em nossa experiência profissional, observamos que a relação entre muitas enfermeiras e clientes que atuam no campo obstétrico com o objetivo de implementar práticas obstétricas humanizadas, envolve o ensinar e o aprender em uma via de mão dupla, algumas vezes concretizando e abrindo possibilidades para a construção compartilhada do conhecimento.

Frente a esta discussão, voltamos nosso olhar especificamente para a Casa de parto David Capistrano Filho da Secretaria Municipal de Saúde do Rio de Janeiro onde observamos que as enfermeiras realizam um amplo trabalho de incentivo ao parto humanizado utilizando-se das práticas educativas como instrumento de cuidar para favorecer a escolha das muIheres pelo tipo de parto e seu empoderamento para a condução de um parto ativo.

Diante do exposto, este estudo teve como objetivo o de discutir as repercussões das práticas educativas desenvolvidas por enfermeiras na Casa de Parto David Capistrano Filho sobre a vivência das mulheres de sua gravidez e de seu parto.

\section{MÉTODO}

Este estudo foi desenvolvido com abordagem qualitativa, que tem o potencial de esclarecer os problemas surgidos do cotidiano da prática das profissões por propiciar que nos debrucemos sobre as singularidades e particularidades vivenciadas nos cenários onde atuam os profissionais de saúde, podendo responder a questões muito particulares quando se preocupa com um nível de realidade que não pode ser quantificado. Sendo assim, essa abordagem trabalha com o universo de significados, motivos, aspirações, crenças, valores e atitudes ${ }^{(9)}$.

O cenário da pesquisa foi a Casa de Parto David Capistrano Filho. Inaugurada no dia 08 de Março de 2004. Esta Instituição funciona na zona oeste do Município do Rio de Janeiro, área habitada prioritariamente por uma população de baixa renda, e caracteriza-se como uma unidade autônoma e isolada, já que não está acoplada ao hospital ${ }^{(10)}$.

Os Centros de Parto Normal ou Casas de Parto são unidades de saúde que atendem as gestantes e parturientes sem riscos obstétricos e desenvolvem práticas obstétricas do modelo humanizado. Essas instituições devem estar inseridas no sistema de saúde local, atuando de maneira complementar às unidades de saúde existentes. São organizados no sentido de promover a ampliação do acesso, do vínculo e do atendimento, humanizando o cuidado obstétrico à gestante e incentivando o parto normal sem intervenções invasivas à fisiologia do corpo feminino ${ }^{(10)}$. 
Durante o mês de maio de 2007, a amostra pesquisada foi de 16 mulheres, que neste estudo receberam nomes fictícios a fim de mantermos o anonimato. O critério de inclusão foi que as mulheres tivessem participado por três etapas na Casa de Parto: dos encontros nos grupos de gestantes durante o pré-natal, que tivessem parido e que comparecessem nas consultas puerperais.

A técnica de coleta de dados foi feita mediante entrevista semiestruturada pré-agendada por contato telefônico, realizada no ambiente da Casa de Parto, de acordo com a disponibilidade das depoentes, tendo como segundo critério de inclusão o parto ter ocorrido a pelo menos seis meses. Tal intervalo de tempo foi considerado importante para que a mulher vivenciasse e elaborasse um discurso com relação à experiência passada.

A entrevista foi estruturada com a seguinte pergunta norteadora: Quais as repercussões das práticas educativas vivenciadas na Casa de Parto em sua gravidez e no seu parto? Para a realização da entrevista foi utilizado o gravador e uma leitura conjunta do termo de autorização, entendimento e consentimento prévio assinado pela depoente. O Projeto foi submetido ao Comitê de Ética em Pesquisa da Secretaria Municipal de Saúde do Rio de Janeiro e aprovado sob o protocolo número 32/07.

A análise ocorreu mediante as diretrizes de análise de conteúdo de Bardin. Assim, na ordenação dos dados foram realizadas as transcrições das gravações, a releitura do material e a organização dos depoimentos. Após esta etapa procedeu-se a classificação dos dados onde houve a identificação das unidades de registro com uma numeração específica e o agrupamento dessas unidades em categorias ${ }^{(11)}$.

\section{RESULTADOS}

Ao analisarmos as repercussões das práticas educativas sobre a vivência da gravidez construímos as seguintes categorias: favorecimento da tranquilidade, favorecimento do vínculo mãe-bebê e melhor aceitação da gravidez, promoção da livre expressão sobre sexualidade.

\section{Favorecimento da tranquilidade}

Nas falas das mulheres evidenciamos que as enfermeiras durante as práticas educativas no período gestacional, transmitiam tranquilidade em sua atitude quando esclareciam as dúvidas:

Eu ficava tranqüila com as palestras e com a tranqüilidade que as enfermeiras passavam pra gente. Toda vez que eu tinha uma dúvida, a próxima palestra tirava essa dúvida. Eu me tranqüilizava mais ainda e eu achei assim, tudo que eu passei aqui, ajudou muito na minha vida. Eu passei uma gravidez ótima. Foi muito tranqüila minha gravidez. (Edymara)

\section{Favorecimento do vínculo mãe-bebê e melhor aceitação da gravidez}

Nas falas abaixo, observamos que as práticas educativas realizadas com as gestantes na Casa de Parto favoreceu a construção do vínculo com o bebê que se transformou, mais tarde, em responsabilidade com o filho:
Foi uma experiência tão ... que se tivesse tido em outro lugar, não sei se teria sido desse jeito. Foi o começo de uma coisa assim inexplicável porque hoje eu olho pra minha filha e estou percebendo que eu acompanhei todos os passos. Desde o começo, com vocês me ajudando. Coisa que eu vejo que eu sou capaz de fazer hoje, com certeza eu aprendi aqui. Os grupos são muito importantes. (Leila)

[...] Eu acho que esse tempo de pré-natal, esse tempo de grupo, me fez perceber muita coisa. Eu não estou sozinha, eu saía, não ligava pra nada. Agora eu saio e caramba tem que ligar pra casa, não sei como a Raíssa está, será que a Raíssa acordou, será que eu posso beber um pouco mais, acho que muda tudo, muda tudo. (Ludimila)

Em outro depoimento, a mulher, que já tinha decidido manter sua gravidez, demonstra no ato simbólico de acariciar a barriga, sua melhor aceitação da mesma:

[...] Eu aceitei melhor a minha gravidez aqui. Eu aceitei e aprendi a fazer carinho na minha barriga. (Tatiana)

\section{Promoção da livre expressão sobre sexualidade}

As práticas educativas desenvolvidas pelas enfermeiras promoveram uma liberdade nas gestantes para falarem sobre sua sexualidade e seus medos em relação ao ato sexual:

[...] Tem muita mulher que não tem nenhum tipo de ato sexual [na gravidez], porque tem medo. A gente pode estar mais aberta se pode ou se não pode. ( Débora)

[...] Quando a gente vem naquela roda de conversa. Aí falam, vocês já voltaram a ter relação? Não porque os outros falam que fica maluca. A gente sempre debate sobre as coisas. Vocês respeitam a gente como a gente respeita vocês. (Ana Beatriz)

\section{Repercussões das práticas educativas sobre a vivência do parto}

Quando focamos a análise nas repercussões das práticas educativas elaboradas pelas enfermeiras na vivência do parto, encontramos mulheres que apresentaram vivências distintas. Para esta temática, elaboramos as seguintes categorias: a presença da cultura medicalizada no comportamento das mulheres, desmistificação da dor do parto, empoderamento, vivenciar o apreendido. A primeira categoria possui duas subcategorias que foram denominadas de falta de posicionamento ativo no parto e redução da capacidade de suportar a dor.

\section{Presença da cultura medicalizada no comportamento das mulheres}

Apesar das enfermeiras da Casa de Parto utilizar em suas práticas educativas, estratégias pedagógicas que estimulam o protagonismo das mulheres, evidenciamos em nossa pesquisa que algumas não conseguem ter um posicionamento ativo no seu parto, pois como podemos observar nas falas abaixo, as depoentes tiveram atitudes que demonstraram submissão 
frente ao profissional, quando aceitaram ordens e até mesmo na posição deitada adotada pela parturiente:

Tudo que vocês mandavam eu fazer eu fiz. A bola, o banquinho. Mandou eu sentar eu sentava, mandou tomar um banho pra relaxar eu ia. (Telma)

Eu deitei na banheira, deitei na cama, mas não consegui. Acabei indo pra sala mesmo [sala de parto]. Acho que o que atrapalhou tudo foi o meu nervosismo.(Maria de Fátima)

Outras, diante dos efeitos da medicalização da dor em nossa sociedade, manifestaram pouca tolerância para suportá-la:

Assim, o meu parto assim, eu achei, na minha opinião, que eu sofri um bocado. Mas eu achei que de repente na maternidade eu poderia ter sofrido mais ainda. [...] Por mais que tenham falado tudo pra mim, eu não imaginava o que eu ia passar, sofrer tanto aquilo que eu sofri [...] Então eu achei que doze horas que eu sofri, eu sofri porque tinha que sofrer. [...]Eu... foi uma dor muito imensa que eu não quero saber mais não. Não quero passar por isso não. (Telma)

Tal insuportabilidade à dor do parto faz com que a mulher solicite o uso de ocitócicos e da episiotomia, que são procedimentos altamente invasivos e contrários à filosofia de trabalho humanizado da enfermeira na Casa de Parto:

E assim, eu pedia as enfermeiras, por favor, me bota no soro. Então eu achei que deveriam ter me botado no soro um pouquinho antes, de repente ter dado um corte pra poder me ajudar. (Telma)

\section{Desmistificação da dor do parto}

Nesta categoria, as depoentes demonstraram em seus depoimentos que as práticas educativas proporcionaram uma oportunidade para que elas confrontassem um novo conhecimento com os que foram adquiridos durante seu processo de socialização. O depoimento abaixo mostra que ao processar os valores partilhados nas dinâmicas das práticas educativas, muitas muIheres desmistificaram a dor e o sofrimento do parto, tanto que não tiveram esses sentimentos na intensidade que esperavam:

Aquelas dores que todo mundo fala não senti. Senti mesmo na hora que ela tava nascendo, agora antes na evolução, na contração, não senti. (Helen)

Todo mundo falava que eu ia sentir muita dor, que eu ia sofrer muito e não foi nada disso. Nenhuma das duas. [...] Não foi tão doloroso quanto eu imaginei que fosse, que essa dor que eu não ia resistir, que eu ia desmaiar. Chegou na hora não foi nada daquilo. (Patrícia)

Porque os outros quando eu tava grávida do meu primeiro filho passava que era horrível. Que dor de parto é a pior dor que tem. Eu não acho. Acho que a pior dor que tem é dor de rins, dor de cabeça, dor de dente. Acho que essas são as piores dores do que a dor de parto. Porque a dor de parto é uma realização da mulher. Cada mulher tem que ter uma conduta de botar aquilo na cabeça e não ter medo e ser mais orientada. Procurar mais orientação sobre parto. Ler mais. Revista, jornal ou conversar com quem tem mais experiência. (Inaiá)

\section{Empoderamento}

Observamos que o processo educativo presente na Casa de Parto contribuiu para que muitas mulheres, mesmo sentindo dores intensas, fossem capazes de exercer um controle sobre as mesmas:

[...] Não tem noção da dor que eu não sei descrever. Não posso dizer que eu não senti dor. Senti muita, mas dava pra controlar, deu pra controlar. (Ana Beatriz)

Em alguns depoimentos as mulheres demonstraram que estavam confiantes em si mesmas para vivenciar seu parto:

Cheguei até rindo. Porque veio muita gente comigo [...]. Aí o pai da criança estava nervoso e eu falei: espera, eu que tenho que está nervosa... Eu que vou ter filho, não é você. (Rosana)

A minha primeira filha, ela foi nascer depois de 2 horas da minha bolsa rota. Ai ela tava meio azulada. Logo assim que ela saiu, ela não chorou. Minha mãe ficou apavorada e não queria deixar essa nascer aqui. Falei mãe eu sou maior de idade, você não manda em mim e eu vou ter lá, que eu adorei ter filho lá. (Simone)

Eu tava confiante. Pela experiência que a gente teve no grupo, os ensinamentos que ela [a enfermeira] passou, que eu aprendi, eu me senti segura de estar ali. (Célia)

\section{Vivência do apreendido}

A maioria das mulheres entrevistadas aceitou vivenciar o apreendido no processo educativo e reconheceram as estratégias de cuidado utilizadas pela enfermeira como benéficas:

Eu experimentei um pouquinho de tudo. Eu fiquei um pouco na banheira, minha bolsa estourou dentro da banheira. Eu acreditava porque quando eu fui pra banheira, as dores realmente elas diminuem, alivia bem. (Zuleide)

[...]E chegou na hora fizeram massagem, me botaram na bola e realmente senti sensação de alívio. Eu caminhei e foi em meia hora, rapidinho ela nasceu. (Sheila)

\section{DISCUSSÃO}

\section{As repercussões das práticas educativas sobre a vivência da gravidez}

A tranquilidade, muitas vezes, é a abalada durante o processo gestacional, pois nele, as mulheres passam por mudanças biológicas, somáticas, psicológicas, sociais que podem 
gerar sentimentos de preocupação e insegurança. No entanto, a sensação de tranquilidade é fundamental para o exercício prazeroso da maternidade ${ }^{(8)}$.

Nesta pesquisa, observamos que as enfermeiras no período gestacional, passaram tranquilidade às gestantes em sua atitude quando esclareciam as dúvidas. As ações educativas quando são participativas e focadas na atenção integral, proporcionam à mulher uma maternidade segura por desmistificarem crenças e tabus inerentes ao ciclo gravídico-puerperal a partir da reflexão sobre esta fase ímpar da vida ${ }^{(1)}$.

A participação ativa das mulheres no processo reflexivo sobre os seus sentimentos, dúvidas e receios sobre a gravidez está diretamente associado ao fato de estarem inseridas em um grupo com pessoas de interesses próximos. Nesses grupos existem maiores possibilidades de serem ouvidas quando expõem suas dificuldades e de serem compreendidas. Isso transforma os grupos educativos em espaços construtores de instrumentos de melhoria individual e coletiva da qualidade de vida ${ }^{(1-6)}$.

Nos grupos educativos com essas características, existe a construção de uma relação de confiança entre as mulheres e a enfermeira, que no caso desta pesquisa, foi coordenadora do grupo. Nas discussões grupais, é fundamental um posicionamento seguro da enfermeira, no entanto, a sua postura não autoritária diferenciará as ações educativas que compartilham saberes profissionais e saberes populares das que possuem natureza prescritiva e informativa.

As práticas embasadas no modelo preventivista e de transmissão de um conhecimento "superior", criam barreiras, nas relações cliente/profissional/instituição, porque ignoram sua dimensão cultural. O simples ato de transmitir conhecimento não é capaz, isoladamente, de transformar comportamentos e hábitos, assim como não permite o exercício de suas potencialidades, o que em nada contribuirá para a melhoria da saúde das pessoas e famílias ${ }^{(12)}$.

A ação educativa baseada na troca de experiências e conhecimentos de forma ética, flexível, dinâmico, complexo, social, reflexivo, terapêutico, construído na interação entre seres humanos pode se concretizar como instrumento de socialização de saberes, promoção da saúde e prevenção de $\operatorname{agravos}^{(1)}$. Deste modo, os grupos podem ser um canal de favorecimento de vínculos afetivos na gestação e no futuro das relações familiares e sociais. Neste sentido, a partir das vivências nos grupos educativos, algumas depoentes, demonstraram que se aproximam mais de seus bebês e até (re)estruturam sua relação familiar.

A gravidez segue diferentes caminhos na afetividade que pode ir desde amor e ternura, até rejeição e culpa ${ }^{(13)}$. Uma das depoentes vivenciou no momento da gravidez, uma ruptura em sua relação conjugal, o que dificultou inicialmente sua relação com o bebê. Considerando que a maneira como se nasce e se é acolhido no mundo pode definir as relações e comportamentos dos seres humanos, consigo e com o mundo $^{(14,15)}$, neste caso, as ações educativas da enfermeira viabilizou melhor aceitação do bebê pela mãe e um provável acolhimento seguro para o futuro recém-nascido.

As reações das mulheres, inclusive quando se trata da sexualidade, estão ligadas à forma que sua cultura concebe o corpo feminino. Essas reações serão interpretadas e moldadas a partir das experiências das mulheres, o que define suas sensações e atitudes ${ }^{(16-17)}$. Neste sentido, muitas mulheres, por terem sido socializadas em um meio muito repressivo, apresentam-se envergonhadas ao falar de sua sexualidade, e por isso mesmo, não a expressam. No entanto, no período gestacional é muito importante a abordagem desta temática, pois alguns autores apontam para uma íntima relação do parto com o orgasmo, mediada pela utilização dos músculos perineais e pela liberação do "hormônio do amor", a ocitocina, abarcando, portanto, dimensões importantes da sexualidade ${ }^{(14,18)}$.

Ademais, a falta do autoconhecimento corporal a respeito da relação sexual causa medos e ansiedades na mulher e seu companheiro $^{(8)}$. Esse fenômeno pode inclusive levar à abstinência e consequências sérias na relação conjugal.

Observamos que as ações educativas desenvolvidas pelas enfermeiras promoveram uma liberdade nas gestantes para falarem sobre sua sexualidade e seus medos em relação ao ato sexual. A construção de espaços de discussão que levem em consideração crenças, valores e anseios da clientela, contribui para que as pessoas tomem sua decisão sobre promover sua saúde sexual e reprodutiva, pois eles tem a função de facilitar e de promover condições de vida e saúde mais benéficas e qualitativas ${ }^{(1,6,19)}$.

\section{As repercussões das práticas educativas sobre a vivência do parto}

Neste estudo, alguns depoimentos apontaram que as ações educativas da enfermeira não são suficientes para que algumas mulheres transformem sua submissão histórica frente ao profissional e adquiram atitudes ativas frente ao parto.

A falta de autonomia da mulher no trabalho de parto ocorreu diante de um longo processo de medicalização do corpo feminino, onde a transformação da gravidez em doença retirou o parto de seu poder e o passou para as mãos do médico. Ao internalizar esse princípio ao longo de sua vida, as mulheres sentiram-se incapazes de parir e passaram a desejar "o parto médico" que é a cesariana e intervenções que para elas aliviariam a dor ${ }^{(20)}$.

Esses resultados mostram também uma limitação das ações educativas, que dependendo da história de vida de cada muIher, será mais ou menos eficiente para desconstruir valores tão profundos adquiridos, por vezes, através de muitas gerações familiares. Para que as mesmas pudessem romper com este ciclo de submissão, acreditamos que outros aspectos da vida destas mulheres deveriam passar por transformações profundas que as levassem ao pleno exercício de sua cidadania e a ser protagonista da sua história.

Ainda, em alguns casos, os efeitos da educação em saúde podem não ser reestruturantes, mas isso não significa o insucesso das práticas educativas. Estratégias educativas participativas não se constituem de forma imediata. Elas são um caminho longo de construções coletivas no dia-a-dia, provavelmente inacabadas, não havendo fórmulas para a mudança de comportamentos ${ }^{(6)}$, elas têm seus limites e devemos estar preparados para respeitar as diferenças.

É importante então, considerarmos que a bagagem cultural de uma mulher influencia suas atitudes e comportamentos 
durante o trabalho de parto e parto. Neste sentido, a dor do parto é ratificada pela Bíblia Sagrada como castigo pelo pecado original e o medo dessa dor foi construído em nossa cultura durante o processo de medicalização. Tanto a dor como o medo dela são transmitidos de geração em geração e muito interferem no desenvolvimento do trabalho de parto e parto ${ }^{(16)}$.

As mudanças no modo de pensar, no entanto, não dependem apenas dos profissionais. Muito pelo contrário, dependem fundamentalmente do sujeito da ação que é a cliente. Observamos que um grupo de mulheres, após processar a discussão que participou, confronta o novo com sua bagagem anterior e aponta em seus depoimentos uma desmistificação da dor e do sofrimento, mostrando que é possível aumentar a suportabilidade da dor do parto se os profissionais em suas ações educativas estimularem as clientes a vivenciarem suas experiências de maneira ativa e participativa, prevenindo o medo culturalmente propagado sobre a mesma. Muitas delas irão formular seus conceitos e percepções a partir dos momentos vivenciados, sendo capazes de concretizar a maternidade e o parto positivamente ${ }^{(17)}$. A mulher percebe, então, que é capaz de vivenciar as sensações advindas da parturição reconhecendo o poder das sensações da fisiologia de seu corpo.

Deste modo, estar confiante e empoderada significa que a mulher assumiu um comportamento pautado pela fisiologia do seu corpo durante a parturição. Quer dizer, não ser controlada por profissionais ou pelo que eles construíram através dos tempos para elas.

As ações educativas das enfermeiras neste contexto mostram uma faceta bastante libertadora, pois agem como estratégia de reversão dos "efeitos colaterais da medicalização" do parto em nossa sociedade e de maneira muito direta abre perspectivas sociais diferenciadas de conduzir, olhar e vivenciar o processo de nascimento ${ }^{(1)}$. Assim, a educação em saúde pode preparar melhor os participantes das práticas educativas para lidarem com situações reais da vida através de vivências práticas ${ }^{(6)}$, como ter contato com os objetos e procedimentos oferecidos durante o trabalho de parto e parto.

\section{CONCLUSÕES}

Evidenciamos com esse estudo as repercussões das práticas educativas desenvolvidas por enfermeiras na Casa de Parto David Capistrano Filho sobre a vivência da gravidez e do parto. Os resultados mostraram que as práticas educativas favoreceram a vivência tranquila da gestação, o vínculo mãe-bebê e melhor aceitação da gravidez, bem como, promoveu a livre expressão sobre sexualidade.

Observamos também que as práticas educativas elaboradas pelas enfermeiras tiveram repercussões na vivência do parto, pois constatamos mulheres que demonstraram a desmistificação da dor do parto, empoderamento e a vivência do apreendido. Quanto aos limites dessas práticas educativas, houve mulheres que apresentaram a falta de posicionamento ativo no parto e redução da capacidade de suportar a dor como comportamentos da cultura medicalizada.

É notório nos serviços de saúde, seja de cuidado primário, secundário ou terciário, a presença da educação nas práticas assistenciais. Seja nas enfermarias de hospitais, nos postos de saúde ou em outras frentes de trabalho, a enfermeira é o agente potencial de mudança e frequentemente desenvolve ações educativas, abrindo grandes possibilidades de discussão entre senso comum e ciência.

No modelo humanizado desenvolvido na Casa de Parto do Rio de Janeiro, a dimensão educativa permeia todo o processo de cuidar desempenhado pelas enfermeiras. Deste modo, as práticas educativas são ações que transformam a vida de muitas mulheres porque colaboram para que elas mudem a maneira de gestar, parir e nascer.

\section{REFERÊNCIAS}

1. Zampieri MFM, Gregório VRP, Custódio ZAO, Régis, MI, Brasil C. Processo educativo com gestantes e casais grávidos: possibilidade para transformação e reflexão da realidade. Texto \& Contexto Enferm 2010;19(4):719-27.

2. Progianti JM, Costa RF. A negociação do cuidado de enfermagem obstétrica através das práticas educativas na casa de parto. Esc Anna Nery Rev Enferm 2008;12(4):789-92.

3. Ministério da Saúde (Brasil) Secretaria de Atenção à Saúde. Departamento de Ações Programáticas Estratégicas. Política nacional de atenção integral à saúde da mulher: princípios e diretrizes. Brasília: Ministério da Saúde; 2004.

4. Ministério da Saúde (Brasil) Secretaria Nacional de Ações Básicas de Saúde. Divisão Nacional de Educação em Saúde. Educação em Saúde: diretrizes. Brasília: Ministério da Saúde; 1989.

5. Backes VMS, Lino MM, Prado ML, Reibnitz KS, Canaven
BP. Competência dos enfermeiros na atuação como educador em saúde. Rev Bras Enferm 2008;61(6):858-65.

6. Santos RV, Penna CMM. A educação em saúde como estratégia para o cuidado à gestante, puérpera e ao recém-nascido. Texto \& Contexto Enferm 2009;18(4):652-60.

7. Acioli S. A prática educativa como expressão do cuidado em Saúde Pública. Rev Bras Enferm 2008;61(1):117-21.

8. Piccinini CA, Gomes AG, Nardi T, Lopes RS. Gestação e a constituição da maternidade. Psicol Estud 2008;13(1):63-72.

9. Minayo MCS. O desafio do conhecimento: pesquisa qualitativa em saúde. 12. ed. São Paulo: HUCITEC; ABRASCO; 2012.

10. Ministério da Saúde (Brasil) Portaria n 985, de 5 de agosto de 1999. Cria o Centro de Parto Normal no âmbito do SUS. Diário Oficial da União 05 ago 1999.

11. Bardin L. Análise de conteúdo. Lisboa: Edições 70; 2008.

12. MonticelliM, Elsen I. A cultura como obstáculo: percepções 
da enfermagem no cuidado às famílias em alojamento conjunto. Texto \& Contexto Enferm 2006;15(1):26-34.

13. Milbradt V. Afetividade e gravidez indesejada, os caminhos de vínculo mãe-filho. Rev. Pensamento Biocêntrico 2008;9:111-33.

14. Odent M. A cientificação do amor. São Paulo: Terceira Margem; 2005.

15. Leboyer F. Nascer sorrindo. São Paulo: Brasiliense; 2011.

16. Oliveira ASS, Rodrigues DP, Guedes MVC, Felipe GF. Percepção de mulheres sobre a vivência do trabalho de parto e parto. Rev Rene 2010;11(n. ${ }^{\circ}$ esp.):32-41.
17. Davim RMB, Torres GV, Dantas JC. Representação das parturientes acerca da dor do parto. Rev Eletrônica Enferm [periódico na internet]. 2008; [acesso em: 02 nov 2010];10(1):100-109 Disponível em: http://www.fen.ufg. br/revista/v10/n1/v10n1a09.htm.

18. Paciornick M. Aprenda a nascer com os índios: parto de cócoras. São Paulo: Brasiliense; 1984.

19. Savall ACR, Mendes AK, Cardoso FL. Perfil do comportamento sexual na gestação. Fisioter Mov 2008;21(2):61-70.

20. Vieira EM. A medicalização do corpo feminino. Rio de Janeiro: Fiocruz; 2002. 